\title{
Effect of Cholesterol, Stigmasterol and Sitosterol in Artificial Diet on Survival and Development of Helicoverpa Armigera
}

\author{
G Chitti Babu* HC Sharma\#, T Madhumati", G Raghavaiah", KVMK Murthy* \\ ${ }^{I}$ International Crops Research Institute for the Semi-Arid Tropics (ICRISAT), Patancheru, Hyderabad- , \\ Andhra Pradesh, India. \\ ${ }^{2}$ Acharya NG Ranga Agricultural University, Rajendranagar, Hyderabad 500 030, Andhra Pradesh, India. \\ *Corresponding Author: G Chitti Babu, International Crops Research Institute for the Semi-Arid Tropics \\ (ICRISAT), Patancheru, Hyderabad-, Andhra Pradesh, India.
}

\begin{abstract}
Insect cultures maintained under laboratory conditions on semisynthetic diets after $4-5$ generations often experience reduced vigor, survival, fecundity, and egg hatching, even difficulties in molting under certain environmental conditions. Sterols have a major influence on growth and development of insects, and they must meet the sterol requirements from the food source. Therefore, we studied the effect of varying concentrations of different sterols and their combination in a chickpea flour based semi-synthetic artificial diet for maintaining a vigorous and healthy culture of the legume pod borer, Helicoverpa armigera. There was no significant effect of different concentrations of stigmasterols in the artificial diet on larval survival, pupation, adult emergence and fecundity of H. armigera. Larval survival was $95.8-100 \%$ in diets with cholesterol as compared to $87.5 \%$ survival on the control diet. However, adult emergence did not differ significantly between the cholesterol impregnated and control diets. Highest fecundity (509.8 eggs per female) was observed in insects reared on diets with $0.25 \%$ cholesterol in first generation, and $0.2 \%$ cholesterol in the second generation (638.6 eggs per female). Cent percent larval survival was recorded in insects reared on a diet containing all the sterols, and also in diets with the $\beta$-sitosterol, followed by the insects reared on diets with the cholesterol and stigmasterol (97.9\%). Adult emergence ranged from 68.75 to $79.17 \%$, and there were no significant differences among the diets tested. The fecundity was greater $(540.2$ eggs/female) in the diets containing $\beta$-sitosterol, followed by diet containing all the sterols $(509.5$ eggs/female). Lowest fecundity was recorded in insects reared on the control diet (436.7 eggs/female). Although there were no much significant differences in survival and development of $H$. armigera on diets containing varying concentrations of different sterols, the larval survival and pupation increased in diets containing different sterols as compared to the control diet, in addition to that increased fecundity recorded on diets with cholesterol, and a combination of all the sterols. Therefore, it is important to have optimum amounts of the sterols in the artificial diets to maintain insect vigor and fecundity.
\end{abstract}

Keywords: Insect rearing, Helicoverpa amigera, Nutrition, Sterols, Cholesterol, Stigmasterol, and Sitosterol.

\section{INTRODUCTION}

The Cotton bollworm/legume pod borer, Helicoverpa armigera (Hübner) (Lepidoptera: Noctuidae) is one of the most devastating crop pests' worldwide (Fitt, 1989; Sigsgaard et al., 2002; Sharma, 2005). It has been reported to attack more than 181 cultivated and uncultivated species of plants (Manjunath et al., 1985). It is a major pest of Cotton, chickpea, pigeonpea, sunflower, tomato, vegetables and other pulse crops. Sixty cultivated and 67 wild host plants used by H. armigera have been recorded from India (Karim, 2000). The serious pest status of $H$. armigera is mainly due to its physiological, behavioral and ecological characteristics that enable it to survive in diverse habitats. Polyphagy, high mobility, high fecundity and facultative diapause enable it to survive in adverse conditions (Fitt, 1989). ). The extent of losses have been estimated to be over US\$2 billion in the semi-arid tropics, despite application of insecticides costing over $\$ 500$ million annually (Sharma, 2005).

Rearing of phytophagous insects such as $H$. armigera on artificial diets rather than on their host plant is advantageous for a variety of investigations. It is important that the larvae reared under laboratory conditions have characteristics similar in viability, vigor and behavior to the wild populations, and show corresponding resistance to pathogenic viruses, bacteria and fungi (Griffith and Haskell, 1988). 
Although several diets have been developed which can support optimum survival and development of $H$. armigera, there is a continuing problem of loss of viability and vigour in the laboratory populations, resulting in collapse of the insect cultures quite frequently. Chemical composition of artificial diets is unique for each insect species, and requires an optimum balance between the nutritional constituents (sugars, fats, proteins, and minerals), in addition to specific requirements for vitamins, sterols, and essential amino acids.

One of the specific constituents needed in artificial diets of insects, sterols play a major role in the physiological processes of insects. Sterols are essential for the growth and development of all the organisms, including insects. They are used as structural components in cell membranes, and also serve as precursors for the steroid hormones. Lack of sterols in the diet may be manifested in any stages of an insect. Sterol deficiency in the adult female houseflies results in $80 \%$ reduction in egg hatching, although the fecundity is not affected (Nation, 2001). Diets deficient in sterols result in incapability of the insects to molt and they typically die in early instars (Nation, 2001; Genc, 2002).

Insects, unlike plants and vertebrates, are unable to synthesize sterols de novo from the isoprenoid precursors and must acquire sterols from their diet by feeding on plants and or from gut symbionts (Clayton 1964; Kirchner, 1982; Ikekawa et al., 1993; Rees, 1985; Svoboda and Thompson, 1985). Phytophagous insects either use the sterols present in their host plants directly or metabolize them to other sterols to meet their dietary requirements for proper growth and development (Svoboda and Thompson, 1985). Phytophagous insects absorb and utilize a variety of dietary sterols structurally similar to cholesterol as tissue sterols (Kirchner, 1982; Ikekawa et al., 1993). Carnivorous insects can absorb and directly utilize the cholesterol contained in their prey's tissues. For herbivorous insects, obtaining adequate amounts of cholesterol from the host plant poses a serious challenge. If there is limited supply of cholesterol, different sterols can be substituted into membranes to meet the minimum requirement of sterol without any apparent negative effect on development and survival. To meet cholesterol requirements from their diet, most herbivorous insects must metabolize ingested phytosterols into cholesterol or other cholesterol-like molecules. In grasshoppers and other insects, cholesterol is required as a precursor to produce the molting hormone - 20-OH ecdysone (Grieneisen, 1994).

Cholesterol and $\beta$-sitosterol usually satisfies the sterol requirements in many insect species, but a few insects such as Drosophila pachea (Pattern \& Wheeler) are known to require a very specific sterol in the diet, 7-stigmasten-3 $\beta$-ol - an uncommon sterol found in senita cactus, Lophocereus schotti (Nation, 2001). Even trace amounts of lipids or sterols in a diet influence growth and development positively (Vanderzant, 1974). Studies on the sterol structure activity relationships in H. zea (Boisd.) has shown that the type and amount of sterol available in the insect diet influences the growth and development of this insect (Ritter and Nes, 1981). Rath and Agarwal (1988) reported that all the concentrations of sitosterol tested in the artificial diet supported growth of $\mathrm{H}$. armigera till adult emergence, but optimum growth was observed at $0.1 \%$ sitosterol or stigmasterol. The H. zea larvae fed on non-utilizable sterols either died by day 20 or underwent delayed growth and pupation (Nes et al.,1997). The resulting pupae from which the moths emerged, exhibited congenital deformities as compared to the larvae reared on utilizable sterols. Poor survival and reduced performance of diamond back moth, Plutella xylostella (L.) larvae has been observed when reared on stigmasterol diet compared with those reared on sitosterol based diets (Behmer and Grebenok, 1998). Within the larvae reared on a diet containing stigmasterol, there was considerable variation among the individuals in terms of larval and pupal development, weight gain, and fecundity. Minimum quantitative requirement for sterols for Schistocerca americana Drury. has been found to be $0.05 \%$ on dry weight basis (Behmer and Elias, 1999). Increase in the amounts of sterol above 0.05\% concentration did not improve survival and development.

Keeping in view the frequent decline observed in the laboratory culture of $H$. armigera in terms of vigor, fecundity and egg hatching, and the pivotal role played by the sterols in survival and fecundity and egg viability, we tested various sterols at different concentrations in the chickpea flour based artificial diet used for rearing $H$. armigera to determine the type and amount of sterol to be used in the artificial diet for maintaining a vigorous and healthy culture of this insect for use in bioassays in host plant resistance and toxicology. 


\section{Materials AND MeTHODS}

The larvae of $H$. armigera used in the bioassays were maintained in the laboratory at the International Crops Research Institute for the Semi-Arid Tropics (ICRISAT), Patancheru, Andhra Pradesh, India. The laboratory culture has been maintained on chickpea based artificial diet (Armes et al., 1992) at 27 $\pm 2^{0} \mathrm{C}$ for the past 10 years. Filed populations of H. armigera was introgressed with the laboratory culture every six months to maintain the heterogeneity of the population. The neonates were reared for five days in groups of 200 to 250 in $200 \mathrm{ml}$ plastic cups having a 2 to $3 \mathrm{~mm}$ layer of artificial diet on the bottom and sides of the cup. Thereafter, the larvae were transferred individually to six cell-well plates (each cell-well is of $3.5 \mathrm{~cm}$ in diameter and $2 \mathrm{~cm}$ in depth) to avoid cannibalism. Each cell-well had sufficient amount of diet $(7 \mathrm{ml})$ to support larval development until pupation. The pupae were removed from cell-wells, sterilized with $2 \%$ sodium hypochlorite solution (with $4 \%$ available chlorine), and kept in groups of 50 in plastic jars containing moistened vermiculite. Upon emergence, 10 pairs of adults were released in an oviposition cage $(30 \times 30 \times 30 \mathrm{~cm})$. Adults were provided with $10 \%$ sucrose or honey solution (Girijan Co-operative Ltd., Visakhapatnam, India) on a cotton swab for feeding. Diaper liners, which have a rough surface, were provided as a substrate for egg laying. The liners were removed daily, and the eggs sterilized in $2 \%$ sodium hypochlorite solution. The liners were dried under a table fan and then placed inside the plastic cups with artificial diet. The liners were removed after 4 days. Freshly emerged neonate larvae were used for bioassays using diet impregnation assay (Narayanamma et al., 2008).

Diet preparation: All the ingredients (except agar-agar and yeast) were put in a mixing jar along with $150 \mathrm{ml}$ of distilled water and the ingredients blended for one minute. Simultaneously, agar-agar was boiled in $265 \mathrm{ml}$ of distilled water, and then yeast was added, and the boiled again for five minutes. Yeast was mixed with the agar-agar, cooled to nearly $60^{\circ} \mathrm{C}$ ( 2 to 3 minutes), and then mixed with the other diet ingredients and blended for two minutes. The diet thus prepared was dispensed into multi-cellular cell wells $(7 \mathrm{ml})$, and kept under a laminar flow with UV light for drying for 30 minutes. The culture was maintained at $25 \pm 1{ }^{\circ} \mathrm{C}$ temperature, $65 \pm 5 \%$ relative humidity, and 14: 10 light: photoperiod.

Cholesterol $(0,0.1,0.15,0.2,0.25$ and $0.3 \%), \beta$-sitosterol $(0,0.005,0.01,0.015$ and $0.02 \%)$ and stigmasterol $(0,0.0125,0.025,0.0375$ and $0.05 \%)$ were tested individually at different concentrations in the chickpea flour based artificial diet (Armes et al., 1992). All the sterols were mixed with the semi-synthetic diet as required. A total of $400 \mathrm{ml}$ diet was prepared and dispensed into the sterilized cell wells. The cell wells were kept under UV light for sterilization. After solidification of the diet, 12 neonate larvae were released carefully with a camel hair brush individually, and the cell wells were sealed with a cling film to prevent the escape of neonate larvae. There were 12 larvae in each replication, and there were four replications for each concentration in a completely randomized design. The most effective concentration of all the sterols [cholesterol $(0.25 \%), \beta$-sitosterol $(0.06 \%)$ and stigmasterol $(0.025 \%)$ ] was also tested in combination in the diet for their effect on survival and development of $H$. armigera. Data were recorded on larval survival (at $10^{\text {th }}$ day), percentage pupation and adult emergence, larval and pupal weights, and fecundity.

\section{Statistical analysis}

Data were subjected to analysis of variance using Genstat version 14.0. Significance of differences between the genotypes was tested by F-test, while the treatment means were compared by least significant difference (LSD) at P 0.05 .

\section{RESUltS}

\section{Effect of stigmasterol on postembryonic development and fecundity of $\boldsymbol{H}$. armigera}

There were no significant differences in larval, pupal and adult survival of $H$. armigera in diets with different amounts of stigmasterol in the artificial diet in first and second generations. However, significant effects of stigmasterol on survival of larvae, pupae and adults were observed in the third generation. The larval survival ranged from $85.4-97.9 \%$ in the first generation, $95.83-100 \%$ in the second generation, and $85.4-97.9 \%$ in the third generation (Table 1). The highest larval survival (97.9 - 100\%) was observed in diets with $0.04 \%$ stigmasterol, and the lowest $(85.3-95.6 \%)$ in insects reared on the control diets in all the three generations. The larval weights ranged from 350.7 - 
Effect of Cholesterol, Stigmasterol and Sitosterol in Artificial Diet on Survival and Development of Helicoverpa Armigera

$382.5 \mathrm{mg}$ in first generation, $363.9-379.1 \mathrm{mg}$ in the second generation and $344.3-367.6 \mathrm{mg}$ in the third generation. The diets with $0.025 \%$ stigmasterol showed a significant effect on larval weights in the third generation (Table 3). Stigmasterol concentrations $>0.025 \%$ did not affect larval survival and development.

Table 1. Effect of different amounts of stigmasterol in artificial diet on postembryonic development and survival of $H$. armigera.

\begin{tabular}{|l|c|c|c|c|c|c|c|c|c|}
\hline \multirow{2}{*}{$\begin{array}{l}\text { Stigma } \\
\text { sterol (\%) }\end{array}$} & \multicolumn{3}{|c|}{ Larval survival } & \multicolumn{3}{c|}{$\begin{array}{c}\text { Pupation } \\
(\%)\end{array}$} & \multicolumn{3}{c|}{$\begin{array}{c}\text { Adult emergence } \\
(\%)\end{array}$} \\
\cline { 2 - 10 } & Gen I & Gen II & Gen III & Gen I & Gen II & Gen III & Gen I & Gen II & Gen III \\
\hline 0.00 & 93.75 & 95.83 & 85.42 & 89.58 & 89.58 & 75.00 & 79.17 & 77.08 & 66.67 \\
\hline 0.0125 & 85.42 & 95.83 & 95.83 & 85.42 & 91.67 & 81.25 & 79.17 & 81.25 & 70.83 \\
\hline 0.025 & 93.75 & 97.92 & 95.83 & 91.67 & 95.83 & 89.58 & 81.25 & 83.33 & 77.08 \\
\hline 0.0375 & 95.83 & 100.00 & 97.92 & 93.75 & 97.92 & 93.75 & 83.33 & 89.58 & 87.50 \\
\hline 0.04 & 97.92 & 100.00 & 97.92 & 97.92 & 95.83 & 87.50 & 85.42 & 85.42 & 85.42 \\
\hline Fp (4,15) & 0.09 & 0.29 & 0.005 & 0.13 & 0.17 & 0.008 & 0.62 & 0.07 & 0.004 \\
\hline VR & 2.44 & 1.36 & 5.56 & 2.08 & 1.84 & 5.07 & 0.67 & 2.68 & 6.10 \\
\hline SE \pm & 0.37 & 0.21 & 0.27 & 0.39 & 0.30 & 0.39 & 0.40 & 0.34 & 0.44 \\
\hline LSD (P 0.05) & NS & NS & 0.80 & NS & NS & 1.18 & NS & NS & 1.32 \\
\hline
\end{tabular}

NS = Nonsignificant.

Table 2. Effect of different amounts of stigmasterol in the artificial diet on postembryonic development of $H$. armigera.

\begin{tabular}{|l|c|c|c|c|c|c|}
\hline \multirow{2}{*}{$\begin{array}{l}\text { Stigma sterols } \\
(\%)\end{array}$} & \multicolumn{3}{|c|}{$\begin{array}{c}\text { Larval period } \\
\text { (days) }\end{array}$} & \multicolumn{3}{c|}{$\begin{array}{c}\text { Pupal period } \\
\text { (days) }\end{array}$} \\
\cline { 2 - 7 } & Gen I & Gen II & Gen III & Gen I & Gen II & Gen III \\
\hline 0 & 15.7 & 15.8 & 15.8 & 8.85 & 9.18 & 9.35 \\
\hline 0.0125 & 15.7 & 15.9 & 15.7 & 8.78 & 9.05 & 9.10 \\
\hline 0.025 & 15.9 & 16.0 & 16.1 & 8.93 & 9.00 & 9.20 \\
\hline 0.0375 & 15.8 & 15.7 & 15.7 & 8.73 & 8.93 & 9.15 \\
\hline 0.04 & 15.6 & 15.8 & 15.8 & 8.98 & 9.03 & 9.13 \\
\hline Fp $(4,15)$ & 0.57 & 0.66 & 0.31 & 0.49 & 0.60 & 0.17 \\
\hline VR & 0.75 & 0.61 & 1.29 & 0.89 & 0.7 & 1.81 \\
\hline SE + & 0.140 & 0.15 & 0.14 & 0.110 & 0.109 & 0.07 \\
\hline LSD $(\mathrm{p} 0.05)$ & NS & NS & NS & NS & NS & NS \\
\hline
\end{tabular}

NS- Non significant.

Table 3. Effect of stigmasterol in the artificial diet on larval and pupal weights of H. armigera.

\begin{tabular}{|l|c|c|c|c|c|c|}
\hline \multirow{2}{*}{$\begin{array}{c}\text { Stigmasterol } \\
(\%)\end{array}$} & \multicolumn{3}{|c|}{ Larval weight(mg) } & \multicolumn{3}{c|}{$\begin{array}{c}\text { Pupal weight } \\
\text { (mg) }\end{array}$} \\
\cline { 2 - 7 } & Gen I & Gen II & Gen III & Gen I & Gen II & Gen III \\
\hline 0.00 & 350.7 & 363.9 & 344.3 & 308.3 & 304.3 & 302.8 \\
\hline 0.0125 & 347.2 & 371.9 & 361.4 & 315.5 & 309.5 & 285.6 \\
\hline 0.025 & 379.2 & 367.6 & 367.6 & 313.5 & 295.0 & 301.5 \\
\hline 0.0375 & 382.5 & 371.0 & 351.0 & 296.8 & 266.3 & 314.1 \\
\hline 0.04 & 376.8 & 374.1 & 362.1 & 303.1 & 291.6 & 302.4 \\
\hline Fp (4,15) & 0.164 & 0.3 & 0.624 & 0.73 & $<0.001$ & 0.086 \\
\hline VR & 1.890 & 1.32 & 0.67 & 0.510 & 14.330 & 2.51 \\
\hline SE + & 0.012 & 0.006 & 0.011 & 0.005 & 0.004 & 0.006 \\
\hline LSD (P 0.05) & NS & NS & NS & NS & 0.013 & NS \\
\hline
\end{tabular}

NS- Non-significant.

Pupation ranged from 85.4 - 97.9, 89.5 - 97.9 and 75.0 - 93.7\% in the first, second and third generations, respectively. Highest pupal recovery was observed in insects reared on diets with $0.0375 \%$ stigmasterol in the second and third generations. The differences in percentage pupation were significant in the third generation. The pupal weights ranged from $296.8-315.5 \mathrm{mg}$ in first generation, but decreased slightly in the following generations $(266.3-304.3$ and $285.6-314.1 \mathrm{mg}$ in the second and third generation, respectively). There was no effect of stigmasterol on pupal survival. The adult emergence ranged from $79.2-85.4 \%$ in the first generation, but the differences in adult 
Effect of Cholesterol, Stigmasterol and Sitosterol in Artificial Diet on Survival and Development of Helicoverpa Armigera

emergence across concentrations were not significant. However, significant effects of stigmasterol on adult emergence were recorded in the $2^{\text {nd }}$ and $3^{\text {rd }}$ generations. Adult survival ranged from 77.1 - 89.6, $66.7-87.5 \%$ in the second and third generations, respectively. A decrease in adult survival was observed in insects reared on the control diet, whereas adult emergence increased in insects reared on diets with stigmasterol. The fecundity ranged from 445 - 513, 422 - 484, 431 - 491eggs/female in the first, second, third generations, respectively (Table 4). There were no significant effects of different concentrations of stigmasterol on the fecundity of $H$. armigera females.

Table 4. Effect of stigmasterol in the artificial diet on fecundity of gram pod borer, H. armigera.

\begin{tabular}{|l|c|c|c|}
\hline \multirow{2}{*}{ Stigmasterol (\%) } & \multicolumn{3}{|c|}{ Eggs /female } \\
\cline { 2 - 4 } & Gen I & Gen II & Gen III \\
\hline 0.00 & 445.2 & 422.6 & 431.4 \\
\hline 0.0125 & 480.6 & 479.0 & 491.6 \\
\hline 0.025 & 476.8 & 462.6 & 491.8 \\
\hline 0.0375 & 513.2 & 484.0 & 477.4 \\
\hline 0.04 & 475.6 & 453.8 & 455.4 \\
\hline Fp (4,15) & 0.71 & 0.45 & 0.57 \\
\hline VR & 0.54 & 0.97 & 0.75 \\
\hline SE + & 32.80 & 24.80 & 30.00 \\
\hline LSD (P 0.05) & NS & NS & NS \\
\hline
\end{tabular}

NS = Non significant.

\section{Effect of cholesterol on postembryonic development and fecundity of $\boldsymbol{H}$. armigera}

In first generation, the larval survival was $100 \%$ in diets with $0.1,0.15,0.2$ and $0.3 \%$ cholesterol as compared to $98 \%$ in diets with no cholesterol. In second generation, the larval survival decreased both in control and cholesterol incorporated diets, possibly because of other factors. The maximum larval survival was $95.8 \%$ in diets with $0.1,0.15,0.2$ and $0.3 \%$ cholesterol as compared to $87.5 \%$ in the control diet (Table 5). The larval period ranged from 19.2 - 21.0 and $17.4-17.7$ days in first and second generations, respectively. The shortest larval period was observed in insects reared on diets without cholesterol. Larval duration increased with an increase in cholesterol concentration in the semi-synthetic diet. The longest larval period was observed in insects reared on diets with $0.3 \%$ cholesterol in the first and second generations (21 and 17.8 days, respectively). The larval weights increased with an increase in cholesterol concentration in the diet up to $0.25 \%$, but it decreased in diets with cholesterol levels $>0.25 \%$. The larval weights were 373.7 and $404.4 \mathrm{mg}$ in diets with $0.25 \%$ cholesterol, while the lowest larval weights of 334.3 and $375.3 \mathrm{mg}$ were observed in insects reared on diets without cholesterol in the first and second generations, respectively.

Table 5. Effect of different amounts of cholesterol in the artificial diets on survival and development of $H$. armigera.

\begin{tabular}{|c|c|c|c|c|c|c|c|c|}
\hline \multicolumn{9}{|c|}{ Generation 1} \\
\hline \multirow{2}{*}{$\begin{array}{l}\text { Cholesterol } \\
(\%)\end{array}$} & \multicolumn{2}{|c|}{$\begin{array}{l}\text { Weight } \\
\text { (mg) }\end{array}$} & \multicolumn{2}{|c|}{$\begin{array}{c}\text { Duration } \\
\text { (days) }\end{array}$} & \multicolumn{3}{|c|}{$\begin{array}{c}\text { Survival } \\
(\%)\end{array}$} & \multirow{2}{*}{$\begin{array}{c}\text { Fecundity } \\
\text { (eggs/ } \\
\text { female) }\end{array}$} \\
\hline & Larva & Pupa & Larva & Pupa & Larval & Pupation & Adult emergence & \\
\hline 0.0 & 349.5 & 325.4 & 19.2 & 10.1 & 97.9 & 79.2 & 66.7 & 385.4 \\
\hline 0.1 & 352.7 & 335.0 & 19.6 & 9.9 & 100 & 83.3 & 72.9 & 474 \\
\hline 0.15 & 373.7 & 325.1 & 20.3 & 9.9 & 100 & 85.4 & 72.9 & 445.8 \\
\hline 0.2 & 355.0 & 297.3 & 20.2 & 9.8 & 100 & 91.7 & 81.3 & 379.8 \\
\hline 0.25 & 351.2 & 305.9 & 20.8 & 10.0 & 95.8 & 91.7 & 77.1 & 509.8 \\
\hline 0.3 & 344.6 & 314.7 & 20.9 & 10.0 & 100 & 95.8 & 79.2 & 452.6 \\
\hline $\mathrm{Fp}(5,18)$ & 0.90 & 0.04 & 0.99 & 0.09 & 0.539 & $<0.001$ & 0.04 & 0.91 \\
\hline VR & 0.32 & 2.95 & 0.005 & 2.23 & 0.84 & 8.49 & 2.88 & 0.289 \\
\hline $\mathrm{SE} \pm$ & 0.02 & 0.01 & 0.301 & 0.07 & 0.23 & 0.26 & 0.37 & 44.10 \\
\hline LSD (P 0.05) & NS & 0.02 & NS & $\mathrm{NS}$ & $\mathrm{NS}$ & 0.76 & 1.11 & NS \\
\hline
\end{tabular}

\section{NS = Non-significant.}

Percentage pupation increased with an increase in cholesterol concentration in the artificial diet, and there were significant differences between the concentrations tested. Pupation ranged from 79.2 - 
Effect of Cholesterol, Stigmasterol and Sitosterol in Artificial Diet on Survival and Development of Helicoverpa Armigera

$85.8 \%$ in the first generation, and lowest pupation was observed in the control diet. In the second generation, lowest pupation $(75.0 \%)$ was observed in the control diet, while highest pupation $(87.5 \%)$ was recorded in diets with $0.15 \%$ cholesterol. The pupal period was 9.4 and 9.8 days in diets with $0.2 \%$ cholesterol and 9.8 and 10.1 days in the control diet in first and second generation, respectively. Cholesterol exhibited a significant effect on pupal weights in the first generation, but not in the second generation. Pupal weights decreased with an increase in cholesterol concentration in the artificial diet. Highest pupal weight $(335.0 \mathrm{mg}$ ) was recorded in diet with $0.1 \%$ cholesterol and the lowest $(297.3$ $\mathrm{mg}$ ) in diet with $0.2 \%$ cholesterol in the first generation. In second generation, the pupal weights were lower in cholesterol incorporated diets (Tables 6).

Table 6. Effect of different amounts of cholesterol in artificial diets on postembryonic development and survival of $H$. armigera.

\begin{tabular}{|c|c|c|c|c|c|c|c|c|}
\hline \multicolumn{9}{|c|}{ Generation 2} \\
\hline \multirow{2}{*}{$\begin{array}{l}\text { Cholesterol } \\
(\%)\end{array}$} & \multirow{2}{*}{$\begin{array}{c}\text { Larval } \\
\text { weight } \\
\text { (mg) }\end{array}$} & \multirow{2}{*}{$\begin{array}{c}\text { Pupal } \\
\text { weight } \\
\text { (mg) }\end{array}$} & \multirow{2}{*}{$\begin{array}{l}\text { Larval } \\
\text { period } \\
\text { (days) }\end{array}$} & \multirow{2}{*}{$\begin{array}{l}\text { Pupal } \\
\text { period } \\
\text { (days) }\end{array}$} & \multicolumn{3}{|c|}{$\begin{array}{c}\text { Survival } \\
(\%)\end{array}$} & \multirow{2}{*}{$\begin{array}{c}\text { Fecundity } \\
\text { (eggs } \\
\text { /female) }\end{array}$} \\
\hline & & & & & Larvae & Pupae & Adult & \\
\hline 0.0 & 375.3 & 310.8 & 17.44 & 9.88 & 87.50 & 75.00 & 64.58 & 493.2 \\
\hline 0.1 & 392.6 & 311.3 & 17.58 & 9.81 & 95.83 & 83.33 & 68.75 & 573.0 \\
\hline 0.15 & 395.9 & 316.2 & 17.79 & 9.75 & 95.83 & 87.50 & 72.92 & 605.6 \\
\hline 0.2 & 401.1 & 309.2 & 17.52 & 9.44 & 95.83 & 85.42 & 66.67 & 638.6 \\
\hline 0.25 & 404.4 & 313.1 & 17.71 & 9.92 & 93.75 & 81.25 & 66.67 & 547.6 \\
\hline 0.3 & 394.9 & 312.4 & 17.60 & 9.79 & 95.83 & 81.25 & 68.75 & 566.2 \\
\hline $\mathrm{Fp}(5,18)$ & 0.007 & 0.164 & 0.77 & 0.004 & 0.242 & 0.251 & 0.813 & 0.645 \\
\hline VR & 4.660 & 1.800 & 0.500 & 5.070 & 1.490 & 1.460 & 0.440 & 0.680 \\
\hline $\mathrm{SE} \pm$ & 0.004 & 0.002 & 0.180 & 0.075 & 0.328 & 0.429 & 0.514 & 60.5 \\
\hline $\mathrm{LSD}(\mathrm{P} 0.05)$ & 0.013 & NS & NS & 0.225 & NS & NS & NS & NS \\
\hline
\end{tabular}

\section{NS = Non-significant.}

There were significant differences in adult emergence in the first generation when the larvae were reared on diets with different amounts of cholesterol. In the second generation, there were no significant differences in adult emergence. The lowest adult emergence was recorded in the control diets in both the generations (66.7 and 64.5\%, respectively). Adult emergence increased with an increase in the cholesterol concentration in the artificial diet. However, adult emergence decreased in diets with 0.2 to $0.3 \%$ cholesterol. The fecundity of insects reared on cholesterol incorporated diets was greater on diets with cholesterol as compared to the insects reared on diets without cholesterol. Highest fecundity (509.8 eggs/female) was observed in insects fed on diets with $0.25 \%$ cholesterol in the first generation, and $0.2 \%$ cholesterol (638.6 eggs/female) in the second generation. The lowest fecundity was observed in insects fed on diets without cholesterol in both the generations (385.4 and 493.2 eggs/female).

Table 7. Effect of different amounts of $\beta$-sitosterol in artificial diets on postembryonic development and survival of $H$. armigera.

\begin{tabular}{|c|c|c|c|c|c|c|}
\hline \multirow{3}{*}{$\begin{array}{l}\beta \text {-sitosterol } \\
(\%)\end{array}$} & \multicolumn{3}{|c|}{ Generation I } & \multicolumn{3}{|c|}{ Generation II } \\
\hline & \multicolumn{6}{|c|}{ Survival (\%) } \\
\hline & Larva & Pupation & Adult emergence & Larva & Pupation & Adult emergence \\
\hline Control & 90.0 & 83.3 & 66.7 & 91.7 & 77.1 & 62.5 \\
\hline 0.02 & 93.3 & 91.7 & 76.7 & 93.8 & 79.2 & 66.7 \\
\hline 0.04 & 96.7 & 88.3 & 75.0 & 93.8 & 81.3 & 68.8 \\
\hline 0.06 & 98.3 & 96.7 & 81.7 & 93.8 & 81.3 & 66.7 \\
\hline 0.08 & 90.0 & 85.0 & 73.3 & 95.8 & 79.2 & 66.7 \\
\hline $\mathrm{Fp}(4,15)$ & 0.08 & 0.05 & 0.09 & 0.93 & 0.95 & 0.92 \\
\hline VR & 2.51 & 3.15 & 2.45 & 0.20 & 0.16 & 0.22 \\
\hline $\mathrm{SE} \pm$ & 0.36 & 0.45 & 0.52 & 0.39 & 0.52 & 0.57 \\
\hline LSD (P 0.05) & 1.08 & 1.36 & $\mathrm{NS}$ & NS & $\mathrm{NS}$ & NS \\
\hline
\end{tabular}

NS = Non-significant. 
Effect of Cholesterol, Stigmasterol and Sitosterol in Artificial Diet on Survival and Development of Helicoverpa Armigera

\section{Effect of $\beta$-sitosterol on postembryonic development and fecundity of $\boldsymbol{H}$. armigera}

The $\beta$-sitosterol incorporated diets supported the growth and development of $H$. armigera up to adult emergence, but the differences between the concentrations tested were not significant. Larval survival ranged from $90.0-98.3 \%$ in first generation and $91.7-95.8 \%$ in the second generation (Table 7). Although larval survival was greater in diets with $\beta$-sitosterol as compared to the control diet, the differences were non-significant. Larval survival increased with an increase in $\beta$-sitosterol concentration in the artificial diet. The larval period did not differ significantly in diets with different amounts of $\beta$-sitosterol. Larval period lasted for 15.8 - 16.0 days in first generation, and 15.1 - 15.8 days in the second generation. Shortest larval period was recorded in diets without $\beta$-sitosterol. Differences in larval weights were significant, and maximum larval weights were recorded in diets with $0.08 \% \beta$-sitosterol in the first generation $(410.7 \mathrm{mg})$, and in diets with $0.04 \% \beta$-sitosterol in the second generation $(458.8 \mathrm{mg}$ ) (Table 8 ). Lowest larval weights were observed in insects reared on the control diets in both the generations (380.0 and $420.9 \mathrm{mg}$, respectively).

Table 8. Effect of different amounts of $\beta$-sitosterol in artificial diets on postembryonic development and survival of $H$. armigera.

\begin{tabular}{|c|c|c|c|c|c|c|c|c|}
\hline \multirow{3}{*}{$\begin{array}{l}\beta \text {-sitosterol } \\
(\%)\end{array}$} & \multicolumn{4}{|c|}{ Generation I } & \multicolumn{4}{|c|}{ Generation II } \\
\hline & \multicolumn{2}{|c|}{$\begin{array}{l}\text { Weight } \\
\text { (mg) }\end{array}$} & \multicolumn{2}{|c|}{$\begin{array}{c}\text { Duration } \\
\text { (days) }\end{array}$} & \multicolumn{2}{|c|}{$\begin{array}{c}\text { Weight } \\
\text { (mg) }\end{array}$} & \multicolumn{2}{|c|}{$\begin{array}{c}\text { Duration } \\
\text { (days) }\end{array}$} \\
\hline & Larva & Pupa & Larva & Pupa & Larva & Pupa & Larva & Pupa \\
\hline Control & 380.0 & 295.1 & 15.8 & 9.1 & 420.9 & 343.2 & 15.1 & 10.4 \\
\hline 0.02 & 396.5 & 309.2 & 15.8 & 8.9 & 443.8 & 343.4 & 15.7 & 10.5 \\
\hline 0.04 & 383.4 & 310.6 & 15.9 & 9.3 & 458.8 & 344.7 & 15.5 & 10.5 \\
\hline 0.06 & 409.6 & 304.0 & 16.0 & 9.0 & 450.7 & 344.7 & 15.6 & 10.4 \\
\hline 0.08 & 410.7 & 310.9 & 15.8 & 9.2 & 452.7 & 346.0 & 15.8 & 10.9 \\
\hline $\mathrm{Fp}(4,15)$ & 0.04 & 0.23 & 0.79 & 0.08 & 0.001 & 0.84 & 0.28 & 0.59 \\
\hline VR & 3.32 & 1.60 & 0.41 & 2.51 & 7.90 & 0.35 & 1.41 & 0.72 \\
\hline $\mathrm{SE} \pm$ & 7.84 & 5.27 & 0.13 & 0.10 & 5.21 & 1.90 & 0.20 & 0.25 \\
\hline $\mathrm{LSD}(\mathrm{P} 0.05)$ & 23.63 & $\mathrm{NS}$ & NS & NS & 15.70 & NS & $\mathrm{NS}$ & $\mathrm{NS}$ \\
\hline
\end{tabular}

\section{NS = Non-significant.}

Table 9. Effect of different amounts of $\beta$-sitosterol in artificial diets on fecundity of H.armigera

\begin{tabular}{|l|c|c|}
\hline \multirow{2}{*}{$\begin{array}{l}\boldsymbol{\beta} \text {-sitosterol } \\
\text { ( })\end{array}$} & Gen I & Eggs /female \\
\cline { 2 - 3 } & 440.4 & Gen II \\
\hline Control & 407.0 & 488.8 \\
\hline 0.02 & 416.8 & 398.2 \\
\hline 0.04 & 410.8 & 596.6 \\
\hline 0.06 & 395.4 & 552.8 \\
\hline 0.08 & 0.87 & 452.8 \\
\hline Fp (4,15) & 0.30 & 0.22 \\
\hline VR & 29.96 & 1.63 \\
\hline SE \pm & NS & 59.83 \\
\hline LSD (P 0.05) & & NS \\
\hline
\end{tabular}

NS-Non- significant.

Table 10. Effect of different sterols in artificial diets on postembryonic development and survival of $H$. armigera.

\begin{tabular}{|l|c|c|c|c|c|c|}
\hline \multirow{2}{*}{ Sterols } & \multirow{2}{*}{$\begin{array}{c}\text { Larval survival } \\
(\mathbf{\%})\end{array}$} & \multirow{2}{*}{$\begin{array}{c}\text { Pupation } \\
(\boldsymbol{\%})\end{array}$} & \multirow{2}{*}{$\begin{array}{c}\text { Adult } \\
\text { emergence }\end{array}$} & \multicolumn{2}{|c|}{$\begin{array}{c}\text { Weight } \\
(\mathbf{m g})\end{array}$} & \multirow{2}{*}{$\begin{array}{c}\text { Fecundity } \\
\text { (eggs /female) }\end{array}$} \\
\cline { 5 - 6 } & & & $\mathbf{\%})$ & Larvae & Pupae & \\
\hline Control & 93.75 & 81.25 & 68.75 & 431.3 & 319.2 & 436.75 \\
\hline Stigmasterol & 97.92 & 85.42 & 70.83 & 450.3 & 333.5 & 503.50 \\
\hline Sitosterol & 100.00 & 91.67 & 77.08 & 430.6 & 322.8 & 540.25 \\
\hline Cholesterol & 97.92 & 89.58 & 77.08 & 444.1 & 327.0 & 494.25 \\
\hline All sterols & 100.00 & 91.67 & 79.17 & 463.5 & 342.3 & 509.50 \\
\hline Fp (4,15) & 0.31 & 0.06 & 0.27 & 0.002 & 0.04 & 0.18 \\
\hline VR & 1.32 & 2.8 & 1.43 & 7.3 & 3.41 & 1.79 \\
\hline SE \pm & 0.27 & 0.32 & 0.45 & 0.005 & 0.005 & 28.22 \\
\hline LSD (P 0.05) & NS & 0.97 & NS & 0.015 & 0.015 & NS \\
\hline
\end{tabular}




\section{NS = Non significant.}

Differences in percentage pupation were significant in the first generation, but non-significant in the second generation. The highest pupation (96.7 and $81.3 \%$, respectively) was recorded in diets with $0.06 \% \beta$-sitosterol in 1 st and 2 nd generations. The lowest pupation $(66.7$ and $77.1 \%)$ was recorded in the control diet. $\beta$-sitosterol showed no significant effects on pupal period. Pupal period lasted for 8.9 - 9.3 days in the first generation and $10.4-10.9$ days in the second generation. Differences in pupal weights were non-significant in both the generations. The highest pupal weights ( 310.9 and $346.0 \mathrm{mg}$ ) were recorded in diets with $0.08 \% \beta$-sitosterol, and the lowest $(295.1$ and $343.2 \mathrm{mg})$ in the control diet in first and second generation, respectively. The adult emergence ranged from $66.7-81.7$ and 62.5 $68.8 \%$ in the first and second generations, respectively. There were no significant effects of $\beta$ sitosterol on adult emergence. The fecundity was lower in $\beta$-sitosterol incorporated diets (395 to 417 eggs/female) as compared to the control diet (440 eggs/female), but the differences were nonsignificant. Fecundity was observed to be decreased with an increase in the concentrations of $\beta$ sitosterol in the artificial diet.

\section{Effect of combination of sterols on postembryonic development and fecundity of $\boldsymbol{H}$. armigera}

Larval survival was $100 \%$ in diets with all the sterols, and also in diets with the $\beta$-sitosterol, followed by the insects reared on diets with the cholesterol and stigmasterol (97.9\%). In the control diet, the larval survival was $93.7 \%$. Larval weight was maximum $(463.5 \mathrm{mg})$ in the larvae were fed on diets containing all the sterols, followed by the insects reared on diets with the stigmasterol $(450.3 \mathrm{mg})$. The least larval weight was observed in the diets with $\beta$-sitosterol $(430.6 \mathrm{mg})$.

Percentage pupation was significantly greater in diets containing a combination of all the sterols, and ranged from $81.25-91.67 \%$. The highest pupation (91.67\%) was recorded in diets with all the sterols and in the diets with $\beta$-sitosterol, followed by diets with cholesterol (89.5\%). Pupal weights ranged from 319.2 - $342.3 \mathrm{mg}$, and the highest pupal weight $(342.3 \mathrm{mg}$ ) was observed in diets containing all the sterols, followed by the insects reared on diets containing stigmasterol $(333.5 \mathrm{mg})$. The least pupal weight was recorded in insects reared on the control diet $(319.2 \mathrm{mg})$. The adult emergence ranged from $68.75-79.17 \%$, and there were no significant differences among the diets tested. The highest adult emergence was recorded in insects reared on diets containing all the sterols and the lowest in the control diet. The fecundity was greater (540.2 eggs/female) in insects reared on diets containing $\beta$ sitosterol, followed by those reared on diets containing all the sterols (509.5 eggs/female). Lowest fecundity was recorded in insects reared on the control diet (436.7 eggs/female).

\section{DisCUSSION}

Sterols play a major role in physiological processes in cell membranes, and as precursors for steroid harmones. Phytophagous insects either use the sterols present in their host plants directly or metabolize them to other sterols to meet their dietary requirements for proper growth and development (Svoboda and Thompson, 1985). Cholesterol is required as a precursor for production of molting harmone - ecdysone (Grieneisen, 1994). To meet the sterol requirements, the phytophagous insects absorb and utilize a variety of dietary sterols structurally similar to cholesterol as tissue sterols from their host plants (Kricher, 1982; Ikekawa et al., 1993). In the present studies, cholesterol exhibited significant effects on the survival and development of H. armigera, indicating that it is essential for growth and survival of this insect. Very low larval mortality was observed when the diets were impregnated with different concentrations of cholesterol. Greater pupation and adult emergence were observed in $H$. armigera larvae reared on cholesterol impregnated diets than in insects reared on the control diet. Although there were no significant effects of cholesterol on fecundity of H. armigera when incorporated in the semi synthetic diet, the larval survival and larval and pupal weights were greater in diets with cholesterol, suggesting that it is important to have optimum amounts of this chemical in the artificial diet. Optimum amounts of cholesterol are needed in the artificial diet to have greater numbers of healthy larvae, pupae and adults. Frankel and Blewett (1943) reported that Tribolium, Silvanus, Lacioderma, Ptinus, Sitoderma, Ephestia grew well when reared on diets with cholesterol. In diets deficient in cholesterol, the insect growth was severely impaired. Cholesterol deterioration did not shorten the lifespan of the adult of $M$. domestica Lin. and the number of eggs laid, but drastically reduced the egg viability (Monroe, 1959). 
In the present studies, the sterol impregnated diets supported the better survival and development of the $H$. armigera, suggesting that sterols are required for better survival and development of this insect. The survival of $H$. armigera larvae was better when all the sterols were incorporated into the artificial diet as compared to the individual sterols. The pupation and adult emergence were also better on diets containing all the sterols. There were significant effects of sterols on larval and pupal development. The larval and pupal weights increased by $10 \%$ in the sterol incorporated diets as compared to the control diets, suggesting that sterols are required for development of $H$. armigera. Behmer and Elias (1999) reported that minimum quantitative need for sterols in $S$. americana Drury was approximately $0.05 \%$ of its dry weight. As sterol quantity increased above $0.05 \%$, the survival and development did not improve proportionaley.

The fermenting vegetarian diet supplemented with $0.01 \%$ cholesterol doubled the egg viability in $M$. domestica. In the present study, the $H$. armigera fecundity increased with an increase in cholesterol concentration in the artificial diet. The fecundity of the insects reared on cholesterol impregnated diets improved up to $80 \%$ as compared to the insects reared on the control diet. Deficiency of sterols in the diet results in incapability of insects to molt, and they typically die in early-instars (Nation, 2001; Genc, 2002). Cholesterol deficiency in adult female house flies results in $80 \%$ reduction in egg hatching, although the fecundity is not affected (Nation, 2001; Genc, 2002). For successful rearing of $H$. armigera, cholesterol is required at a concentration of $0.2-0.25 \%$, and plays an important role in development and fecundity of this insect.

The pupal weights greater in the $\beta$-sitosterol incorporated diets than on the control diet. The highest female cocoon and shell weight has earlier been recorded in $\beta$-sitosterol-treated plants (Neog et al., 2011). The fecundity was low in insects reared on $\beta$-sitosterol incorporated diets as compared to the insects reared on the control diet in first generation. In the second generation, however, the fecundity declined in insects reared on diets with $\beta$-sitosterol. Earlier, Monroe et al. (1961) showed that $\beta$ sitosterol did not improve the fecundity of $M$. domestica even at a concentration of $1.0 \%$. In the present studies, high concentrations of $\beta$-sitosterol did not exhibit any significant effects on survival and development of $H$. armigera. Thus, $\beta$-sitosterol may be of less importance in the dietary requirements of $H$. armigera. Sterols play an important role in survival and development of insects, and artificial diets with optimum quantities of sterols improve development of and fecundity of $H$. armigera. Optimum amounts of cholesterol and/or a combination of all the sterols is important for maintaining a healthy culture of insects for several generations in the laboratory for conducting insect bioassays for host plant resistance, evaluation of transgenic plants and mapping populations, toxicology, and pest management.

\section{ACKNOWLEDGEMENTS}

We thank the Department of Agriculture \& Cooperation, Ministry of Agriculture, Government of India, for providing the financial support, and the staff of entomology for their help in carrying out these studies.

\section{REFERENCES}

Armes N J, Bond G S and Cooter R J 1992 The laboratory culture and development of Helicoverpa armigera. Bulletin - Natural Resources Institute. 57, (3): 22 pp.

Behmer, S.T and Elias, D.O. 1999 Phytosterol structure and its impact on the feeding behaviour of the generalist grasshopper Schistocerca americana. Physiological Entomology. 24, 18-27.

Behmer, S.T., Grebenok, R.J., 1998 Impact of dietary sterols on life-history traits of a caterpillar. Physiological Entomology 23, 165-175.

Clayton, R.B. 1964 The utilization of sterols by insects. Journal of Lipid Research. 5: 3-19.

Fitt G P 1989 The ecology of Heliothis species in relation to agro-ecosystems. Annaul Review of Entomology. 34: 17-52.

Fraenekel, G and Blewett, M. 1943 Sterol requirements of several insects. Biochemistry Journal 37 (6): 692695.

Genc, H. Phaon 2002 Crescent, Phyciodes phaon: Life cycle, nutrional ecology and reproduction, Ph.D. dissertation, University of Florida, Gainesville, FL 32611, USA.

Grieneisen, M.L. 1994 Recent advances in our knowledge of ecdysteroid biosynthesis in insects and crustaceans. Insect Biochemistry and Molecular Biology. 24: 115-132. 
Effect of Cholesterol, Stigmasterol and Sitosterol in Artificial Diet on Survival and Development of Helicoverpa Armigera

Griffith J S R and Haskell T 1988 Culture of Heliothis armigera (Noctuidae: Lepidoptera) using novel group rearing techniques and semi artificial diet. Tropical Pest Management. 34: 349-355.

Ikekawa, N., Morisaki, M and Fujimoto, Y. 1993 Sterol metabolism in insects; Dealkylation of phytosterol to cholesterol. Academy of Chemical Research. 26: 139-146.

Karim, S. 2000 Management of Helicoverpa armigera (Hub.). Pakistan Journal of Biological Sciences. 3: 1213-1222.

Kirchner, H.W. 1982 Sterols and Insects: Cholesterol systems in insects and animals. Dupont. J. ed. CRC press, Boka Raton. 1-50.

Manjunath T M, Bhatnagar V S, Pawar C S and Sitanathan, S 1985 Economic importance of Heliothis sp. in India and an assessment of their natural enemies and host plants. In: Proceedings of a Workshop on Biological Control on Heliothis, Andhra Pradesh, India: International Crops Research Institute for the Semi Arid Tropics, pp. 11-15.

Monroe, R. E. 1959 Role of cholesterol in house fly reproduction. Nature: 184, 1513.

Monroe, R. E., Kaplanis, J. N. and Robbins, W. E. 1961 Sterol storage and reproduction in the house fly. Annals of Entomological Society of America. 54: 537-539.

Narayanamma, V. L., Sharma, H.C. Gowda, C.L.L. and Srinivasulu M. 2008 Incorporation of lyophilized leaves and pods into artificial diets to assess the antibiosis component of resistance to pod borer, Helicoverpa armigera (Lepidoptera: Noctuidae) in chickpea. International Journal of Tropical Insect Science, 27 (3/4): 191-198.

Nation, J. L. 2001 Insect Physiology and Biochemistry. Boca Raton, Fla., CRC Press. 485 pp.

Neog, K., Unni, B and Ahmed, G. 2011 Studies on the influence of host plants and effect of chemical stimulants on the feeding behavior in the muga silkworm, Antheraea assamensis. Journal of Insect Science. 11:133

Nes., D.W. Monica lopez Wen zhou De an guo Patrick F dowd and Robert, A Norton.1997 Sterol utilization and metabolism by Heliothis zea. Lipids. 32: 1317-1323.

Rath, R and Agarwal, H.C. 1988 Growth of gram pod borer, Heliothis armigera (Hubner), in relation to dietary sterols. Indian Journal of Experimental Biology. 26: 993-995.

Rees, H.H. 1985 Biosynthesis of ecdysone, (In G. A. Kerkut and L. I. Gilbert (eds.)). Comprehensive Insect Physiology, Biochemistry and Pharmacology. Pergamon, New York. pp. 249-293.

Ritter, K.S and Nes, W.R. 1981 The effects of cholesterol on the development of Heliothis zea. Journal of Insect Physiology. 27, 175-181.

Sharma H C 2005 Heliothis/Helicoverpa management; emerging trends and strategies for future research. Oxford and IBH Publishers, New Delhi, India. 469.

Sigsgaard L, Greenstone M H and Duffield S J 2002 Egg cannibalism in Helicoverpa armigera on sorghum and pigeonpea. Biological Control. 47: 151-165.

Svoboda, J.A. and Thompson, M.J. 1985 Steroids. In Comprehensive Insect Physiology, Biochemistry and Pharmacology (ed. G. A. Kerkut and L. I. Gilbert), Oxford: Pergamon Press. pp. 137-175.

Vanderzant, E.S. 1974 Development, significance, and application of artificial diets for insects. Annual Review of Entomology. 19: 139-160.

Yelshetty S and Sidde Gowda D K 1998 Progress in pulse entomological research at Gulbarga. Paper presented at the seminar on Progress and Perspectives for Sustainable Agriculture in North Karnataka, Dharwad, $20^{\text {th }}$ March, 1998.

Citation: G Chitti Babu et al., "Effect of Cholesterol, Stigmasterol and Sitosterol in Artificial Diet on Survival and Development of Helicoverpa Armigera", International Journal of Research Studies in Agricultural Sciences, vol. 4, no. 2, p. 34-43, 2018. http://dx.doi.org/10.20431/2454-6224.0402005

Copyright: () 2018 G Chitti Babu et al.. This is an open-access article distributed under the terms of the Creative Commons Attribution License, which permits unrestricted use, distribution, and reproduction in any medium, provided the original author and source are credited. 